\title{
Temporomandibular disorder and comorbid pain conditions
}

\author{
Pei Feng Lim, BDS, MS [clinical assistant professor], \\ Center for Neurosensory Disorders, University of North Carolina, Chapel Hill \\ William Maixner, DDS, PhD [professor], and \\ Center for Neurosensory Disorders, University of North Carolina, Chapel Hill
}

Asma A. Khan, BDS, PhD [assistant professor]

Department of Endodontics, University of North Carolina, 1170 Old Dental Building, CB \#7450, Chapel Hill, N.C. 27599

Asma A. Khan: asma_khan@dentistry.unc.edu

\section{CLINICAL PROBLEM}

A 50-year-old woman who was new to the dental office sought treatment because of a chief complaint of pain in her jaw and teeth "for many years." During a period of several years, she had seen many dentists who had adjusted her occlusion and restored most of her molars in an attempt to eliminate her pain. However, her facial pain condition did not improve with this treatment approach. Her previous dentist made an oral appliance and told her that there was nothing else he could do for her. She reported that the soreness in her jaw and her headaches had worsened lately. The patient's medical history included constant headaches, irritable bowel syndrome, vulvar vestibulitis syndrome and fibromyalgia (FM). Is there an association between her chronic facial pain and these other widespread pain conditions?

\section{EXPLANATION}

Three distinct patterns of pain distribution—localized, regional and widespread—generally are recognized. ${ }^{1,2}$ Various psychological and general health factors have been identified as risk factors for the development of chronic widespread pain (CWP). These include poor general health, sleep disturbance, fatigue and high levels of psychological distress. ${ }^{3,4}$ In a prospective study, Von Korff and colleagues ${ }^{5}$ found that the presence of one pain condition at baseline was associated with a fourfold increased risk of developing a temporomandibular disorder (TMD). In addition, Aggarwal and colleagues ${ }^{6}$ reported that one of the strongest predictors of chronic TMD pain was a history of having had CWP.

The results of various studies have shown that chronic facial pain often is comorbid with other pain conditions including $\mathrm{FM},{ }^{7}$ headaches, ${ }^{8}$ vulvar vestibulitis syndrome (also known

Copyright $\odot 2011$ American Dental Association. All rights reserved.

Address reprint requests to Dr. Khan.

Disclosure. Dr. Maixner is an equity shareholder in and consultant to Algynomics, Chapel Hill, N.C. Drs. Lim and Khan did not report any disclosures.

Pain Update is published in collaboration with the Neuroscience Group of the International Association for Dental Research. 
as vulvodynia), ${ }^{9}$ spinal pain ${ }^{10}$ and low back pain. ${ }^{11}$ The results of a prospective longitudinal study showed that participants who developed TMD reported having had a higher experience of joint, back, chest and menstrual pain at baseline. ${ }^{12}$ They also were more likely to be experiencing other pains at the time of TMD onset compared with participants who did not develop TMD. These findings suggest that, for certain patients, regional and widespread chronic pain conditions represent overlapping conditions and should be considered part of a continuum rather than distinct entities with separate etiologies.

FM represents one end of the CWP continuum. ${ }^{13}$ Study investigators evaluating the overlap between FM and TMD reported that 35 to 97 percent of patients with FM had signs and symptoms of TMD, while the prevalence of FM in patients with TMD was an estimated 10 to 52 percent. ${ }^{14-16}$ These percentages vary widely owing to different inclusion criteria. Similarities reported in the two conditions included typical clinical pain reports, common symptoms such as sleep difficulty and fatigue, and psycho - pathology such as depression and anxiety disorders; again, this suggests that TMD pain in patients with FM may be an extension of the CWP rather than a separate entity.

Diatchenko and colleagues ${ }^{17}$ hypothesized that, irrespective of the peripheral pain location, chronic pain probably is regulated within the body in a similar fashion. These authors proposed that idiopathic pain disorders share common denominators, including exposure to certain environmental events, elevated levels of psychological distress, a tendency toward pain amplification and genetic predisposition. ${ }^{17}$ These pathways of vulnerability are interactive, and as a group they influence the patient's risk of experiencing pain onset and persistence.

Several lines of evidence indicate that alterations in central pain processing play an important role in the onset of CWP, the exacerbation of CWP or both. In an experimental setting, patients with TMD demonstrated abnormal temporal summation (that is, enhanced pain intensity in response to repetitive noxious stimulation), and this enhanced temporal summation usually is not limited to the area of clinical pain. ${ }^{18}$ Functional abnormalities of the hypothalamic-pituitary-adrenal axis, which is the major physiological stress response system in the body, are another hallmark of chronic pain conditions. Light and colleagues ${ }^{19}$ conducted a double-masked, crossover, placebo-controlled trial and reported that propranolol, a $\beta$-adrenergic antagonist, reduced the total number of painful sites and pain ratings in patients with TMD and FM. Taken together, the data from these studies suggest generalized hyperexcitability of the central nociceptive system in patients with chronic pain.

The results of human genetic studies revealed associations between certain genetic polymorphisms and the development of chronic pain syndromes. ${ }^{20,21}$ When coupled with environmental triggers, these genetic factors contribute to enhanced pain perception, psychological dysfunction and an increased risk of onset and persistence of TMD and related idiopathic pain disorders. Diatchenko and colleagues ${ }^{22}$ identified three genetic variants (haplotypes) of the gene encoding catecholamine- $O$-methyltransferase designated as low-, average- and high-pain sensitivity. The presence of even a single low-pain-sensitivity haplotype reduces by 2.3 times the risk of developing TMD. 


\section{CLINICAL IMPLICATIONS}

Increased awareness of the overlap between chronic TMD and comorbid pain conditions likely will result in improved diagnoses and more effective pain management. ${ }^{23}$ Patients with TMD symptoms often are treated within a narrow dental paradigm while clinicians ignore coexisting pain conditions, resulting in treatment failure and perpetuation of the problem. Raphael and Marbach ${ }^{24}$ conducted a randomized, controlled clinical trial, the results of which showed that patients with TMD and widespread pain did not experience improvement with oral appliance therapy, whereas those with only local TMD pain did experience improvement. Researchers in future studies need to address the impact of these pathways of vulnerability on the effectiveness of the various treatment modalities for chronic TMD and comorbid pain disorders.

Various simple self-administered questionnaires are available to aid the general dentist in assessing possible comorbid pain conditions. The Fibromyalgia Rapid Screening Tool is a sixitem inventory requiring "yes" or "no" responses; it has a sensitivity of 90.5 percent and a specificity of 85.7 percent in the detection of FM. ${ }^{25}$ The ID Migraine screener is a threeitem questionnaire also requiring "yes" or "no" responses; it has a positive predictive value of 93 percent. ${ }^{26}$ Practitioners also can assess associated symptoms such as depression and anxiety, somatization, insomnia and fatigue by means of various validated short questionnaires, such as the Beck Depression Inventory ${ }^{27}$ and the State-Trait Anxiety Inventory. ${ }^{28}$

\section{CONCLUSION}

An urgent need exists for a multifaceted approach to the treatment of TMD that is based not only on its etiology but also on the presence or absence of comorbid conditions. According to a recently revised policy statement of the American Association for Dental Research, ${ }^{29}$ "unless there are specific and justifiable indications to the contrary, treatment of TMD patients initially should be based on the use of conservative, reversible and evidence-based therapeutic modalities." These include patient education and self-management, cognitive behavioral therapy, pharmacotherapy, physical therapy and use of orthopedic appliances. In patients with comorbid conditions, however, referral to a multidisciplinary pain clinic for assessment and treatment almost always will produce a better outcome for all concerned.

\section{References}

1. Turp JC, Kowalski CJ, O'Leary N, et al. Pain maps from facial pain patients indicate a broad pain geography. J Dent Res. 1998; 77(6):1465-1472. [PubMed: 9649175]

2. Macfarlane GJ. Generalized pain, fibromyalgia and regional pain: an epidemiological view. Baillieres Best Pract Res Clin Rheumatol. 1999; 13(3):403-414. [PubMed: 10562370]

3. Nicholl BI, Macfarlane GJ, Davies KA, Morriss R, Dickens C, McBeth J. Premorbid psychosocial factors are associated with poor health-related quality of life in subjects with new onset of chronic widespread pain: results from the EPIFUND study (published online ahead of print Dec. 9, 2008). Pain. 2009; 141(1-2):119-126. [PubMed: 19059720]

4. Nahit ES, Hunt IM, Lunt M, Dunn G, Silman AJ, Macfarlane GJ. Effects of psychosocial and individual psychological factors on the onset of musculoskeletal pain: common and site-specific effects. Ann Rheum Dis. 2003; 62(8):755-760. [PubMed: 12860731] 
5. Von Korff M, Le Resche L, Dworkin SF. First onset of common pain symptoms: a prospective study of depression as a risk factor. Pain. 1993; 55(2):251-258. [PubMed: 8309712]

6. Aggarwal VR, Macfarlane GJ, Farragher TM, McBeth J. Risk factors for onset of chronic oro-facial pain: results of the North Cheshire oro-facial pain prospective population study. Pain. 2010; 149(2): 354-359. [PubMed: 20304556]

7. Balasubramaniam R, de Leeuw R, Zhu H, Nickerson RB, Okeson JP, Carlson CR. Prevalence of temporomandibular disorders in fibromyalgia and failed back syndrome patients: a blinded prospective comparison study. Oral Surg Oral Med Oral Pathol Oral Radiol Endod. 2007; 104(2): 204-216. [PubMed: 17482850]

8. Gonçalves DA, Bigal ME, Jales LC, Camparis CM, Speciali JG. Headache and symptoms of temporomandibular disorder: an epidemiological study. Headache. 2010; 50(2):231-241. [PubMed: 19751369]

9. Zolnoun DA, Rohl J, Moore CG, Perinetti-Liebert C, Lamvu GM, Maixner W. Overlap between orofacial pain and vulvar vestibulitis syndrome. Clin J Pain. 2008; 24(3):187-191. [PubMed: 18287822]

10. Marklund S, Wiesinger B, Wänman A. Reciprocal influence on the incidence of symptoms in trigeminally and spinally innervated areas. Eur J Pain. 2010; 14(4):366-371. [PubMed: 19640751]

11. Wiesinger B, Malker H, Englund E, Wänman A. Back pain in relation to musculoskeletal disorders in the jaw-face: a matched case-control study. Pain. 2007; 131(3):311-319. [PubMed: 17459585]

12. Lim PF, Smith S, Bhalang K, Slade GD, Maixner W. Development of temporomandibular disorders is associated with greater bodily pain experience. Clin J Pain. 2010; 26(2):116-120. [PubMed: 20090437]

13. Wolfe F, Clauw DJ, Fitzcharles MA, et al. The American College of Rheumatology preliminary diagnostic criteria for fibromyalgia and measurement of symptom severity. Arthritis Care Res (Hoboken). 2010; 62(5):600-610. [PubMed: 20461783]

14. Leblebici B, Pekta ZO, Ortancil O, Hürcan EC, Bagis S, Akman MN. Coexistence of fibromyalgia, temporomandibular disorder, and masticatory myofascial pain syndromes. Rheumatol Int. 2007; 27(6):541-544. [PubMed: 17096090]

15. Plesh O, Wolfe F, Lane N. The relationship between fibromyalgia and temporomandibular disorders: prevalence and symptom severity. J Rheumatol. 1996; 23(11):1948-1952. [PubMed: 8923373]

16. Aaron LA, Burke MM, Buchwald D. Overlapping conditions among patients with chronic fatigue syndrome, fibromyalgia, and temporomandibular disorder. Arch Intern Med. 2000; 160(2):221227. [PubMed: 10647761]

17. Diatchenko L, Nackley AG, Slade GD, Fillingim RB, Maixner W. Idiopathic pain disorders: pathways of vulnerability. Pain. 2006; 123(3):226-230. [PubMed: 16777329]

18. Sarlani E, Greenspan JD. Why look in the brain for answers to temporomandibular disorder pain? Cells Tissues Organs. 2005; 180(1):69-75. [PubMed: 16088135]

19. Light KC, Bragdon EE, Grewen KM, Brownley KA, Girdler SS, Maixner W. Adrenergic dysregulation and pain with and without acute beta-blockade in women with fibromyalgia and temporomandibular disorder. J Pain. 2009; 10(5):542-552. [PubMed: 19411061]

20. Buskila D, Sarzi-Puttini P, Ablin JN. The genetics of fibromyalgia syndrome. Pharmacogenomics. 2007; 8(1):67-74. [PubMed: 17187510]

21. Diatchenko L, Anderson AD, Slade GD, et al. Three major haplotypes of the beta2 adrenergic receptor define psychological profile, blood pressure, and the risk for development of a common musculoskeletal pain disorder. Am J Med Genet B Neuropsychiatr Genet. 2006; 141B(5):449-462. [PubMed: 16741943]

22. Diatchenko L, Slade GD, Nackley AG, et al. Genetic basis for individual variations in pain perception and the development of a chronic pain condition. Hum Mol Genet. 2005; 14(1):135143. [PubMed: 15537663]

23. Velly AM, Fricton J. The impact of comorbid conditions on treatment of temporomandibular disorders. JADA. 2011; 142(2):170-172. [PubMed: 21282683]

24. Raphael KG, Marbach JJ. Widespread pain and the effectiveness of oral splints in myofascial face pain. JADA. 2001; 132(3):305-316. [PubMed: 11258087] 
25. Perrot S, Bouhassira D, Fermanian J. Cercle d'Etude de la Douleur en Rhumatologie. Development and validation of the Fibromyalgia Rapid Screening Tool (FiRST). Pain. 2010; 150(2):250-256. [PubMed: 20488620]

26. Lipton RB, Dodick D, Sadovsky R, et al. ID Migraine Validation Study. A self-administered screener for migraine in primary care: the ID Migraine validation study. Neurology. 2003; 61(3): 375-382. [PubMed: 12913201]

27. Beck AT, Ward CH, Mendelson M, Mock J, Erbaugh J. An inventory for measuring depression. Arch Gen Psychiatry. 1961; 4:561-571. [PubMed: 13688369]

28. Spielberger, CD.; Gorsuch, RL.; Lushene, RE. Manual for the State-Trait Anxiety Inventory. Palo Alto, Calif.: Consulting Psychologists Press; 1970.

29. American Association for Dental Research. Policy statements: temporomandibular disorders. "www.aadronline.org/i4a/pages/index.cfm?pageid=3465\#TMD". 